\title{
Application and discussion of water reducing agent in concrete
}

\section{(Handan city jianye construction engineering quality test co.Itd Handan city, Hebei province, 056000, China)}

\section{Influence factors of water reducing agent performance}

\section{1 common water reducer}

Cement composition is the main influence factors, common water reducing agent containing mixed materials, gypsum, kinds and contents of tricalcium aluminate, generally, and compared zeolite cream, anhydrite, half water gypsum, the adaptability of dihydrate gypsum is best. For some common water reducer, only two water gypsum can be used, such as magnesium, calcium, sodium, sodium, sodium, etc. In addition, the added in the cement and concrete components, such as clay, ash, fly ash can also affect the performance of water reducing agent, and the component content is higher, the greater the influence on the performance of water reducing agent ${ }^{\mathbf{I}} \mathbf{l}$.

\section{2 effective water reducing} agent

Due to the cement type is more, add in different kinds of cement clinker is also different, if the content of magnesium oxide in cement is high, so when high efficiency water reducing agent is added to the concrete, the greater the impact. For clinker minerals, high efficiency water reducing agent can be selective adsorption, and the different composition of clinker, the high efficiency water reducing agent adsorption weight is different also, if enough adsorption layer, then adsorption weight more; If the adsorption layer is insufficient, then the adsorption component is less. So, the different adsorption layer, the impact of dispersion effect of high efficiency water reducing agent is different also, for the clinker minerals, high efficiency water reducing agent if its adsorption ability stronger, then the intermiscibility, water reducing agent performance won't be able to effectively play out ${ }^{\mathbf{I}_{2} \mathbf{l}}$.

2 Second, the influence factor of concrete slump degree

2.1 in the actual project, we should first know the water reduction rate, then the water reducing agent can be introduced with the caving degree of $20 \mathrm{~mm}$ per $5 \mathrm{~kg}$ of water. The more water reducer content of concrete, the more the collapse of concrete. It's less. Under the same conditions, in the concrete cement mineral content is larger, a large amount of water reducing agent was its adsorption, accounts for the more concrete components, adsorption is insufficient, lead to commercial concrete slump
Abstract:The water reducing agent in the concrete application is very extensive, as a kind of concrete admixture, water reducing agent has been widely used in the concrete development, can be seen as important to the preparation of concrete.

Key words:Water reducing agent slump mixing concrete

Published on 30th Sept,2017

\author{
Corresponding Author: Yang \\ wenping, Handan city jianye \\ construction engineering quality test \\ co.ltd Handan city, Hebei \\ province, 056000, China. \\ 504206828@qq.com,15131753667.
}


loss. This is the root cause of the concrete collapse of the concrete. Therefore, if the high quality concrete of high flow degree is to be produced, and it is required that the slump loss is small, it is advisable to choose a water reducer with high water reduction rate and a small amount of cement ${ }^{[3]}$.

The gypsum of concrete may also have a great influence on the slump loss of the newly mixed concrete. At the same time, the concrete hydration is slowed down by adding a certain amount of gypsum. However, when the gypsum is too large or insufficient, it can accelerate the hydration speed of the cement, resulting in the larger collapse loss of the newly mixed concrete.

2.3 the main factors affecting the slump are the quantity of cement slurry and the consistency, sand rate and the properties, time and temperature of the constituent materials, so it is usually adjusted by adjusting the sand ratio and water ash ratio. Special attention should be made to adjust the amount of water or sand rate to the water ratio, until it meets the requirements. The easiest way to adjust concrete slump is to reduce water consumption, adjust sand rate and adjust admixture. Spent big slump, after mixing method, namely, sand, stone, cement, water (some or all of the water), mix the buckle of mixed water reducing agent again, this kind of method to boycott the mixed water reducing agent of concrete slump loss have obvious effect.

\section{4 the appropriate proportion of} water dewatering agents is between $2.5 \%$ and $4 \%$ of the total amount, generally unfavorable to more than $5 \%$. For gelation materials, the total weight was $0.4 \% \sim 2.0 \%$, and the commonly used amount was $0.4 \% \sim 1.2 \%$. Concrete test and test should be carried out before use for optimum dosage ${ }^{[4]}$.

\section{The influence factors of the dosage of water reducing agent}

3.1 gravel and pebbles as the toppings have a great influence on the flow degree and ease of mixing of concrete. Gravel is used as aggregate, although cement and stone cementing strength is strong, but because of the edges and corners of the gravel, not easy to flow, admixture should increase the amount of admixture accordingly. The pebble is smooth and the admixture can be reduced appropriately.

3.2 fine aggregate is coarse sand, medium sand and fine sand, and different fineness modulus has a great influence on the mixing of concrete and the admixtures of the admixture. When the sand is thick, the flow rate is poor, and the content is increased accordingly. When the sand is fine, the flow is good, and the admixture can be reduced accordingly.

3.3 when using the mixing water has changed, such as the original use tap water in the river later, because of the different water quality, admixture dosage may also be affected by a certain, want to try the first match, the measured orifice size, whether secrete water segregation, whether or not serious, to determine the dosage of admixture.

3.4 the mixing of fly ash and slag powder is more than $5 \%$, and $40 \%$ is also common. These mineral admixtures are not as sensitive to additives as cement, but they also need to consider the compatibility and adaptability of admixtures.

3.5 in the process of concrete mixing, the additive method of admixture has a great influence on the use of admixtures and influences the admixture. For example, the method of adding water - reducing agent can be divided into the first mixing method, the blending method, the stagnant water method and the post-doping method. The admixture is determined according to different addition ${ }^{[5]}$.

\section{Mix proportion design of concrete with water - reducing agent}

When considering a water reducer, the design of the mix shall follow the following principles:

4.1 the amount of cement is the same as that of non-water reducer,

4.2 it is similar to the concrete that does not mix water with water, and USES the water reducing agent to reduce the amount of water used by 
the unit volume concrete (that is, reducing the water ash ratio to increase the strength of concrete).

4.3 sand rate is roughly the same, calculate the amount of sand and stone,

4.4 trial mix and adjustment, if it is too easy, reduce water consumption. If the intensity is satisfied, reduce the dosage of water reducer.

If ever of fresh concrete mixture slump loss is normal, and now the slump loss too fast, will inspect all kinds of raw materials is normal, if the aggregate has not changed much, that is the change led to the cement concrete mixture of these changes, it should be appropriate increase dosage of admixture, in order to make concrete mixture of state meet the construction requirements. It is strictly forbidden to adjust the state of concrete mix by increasing water consumption, so as to avoid the decrease of concrete strength due to the increase of water glue ratio. If the water is bleeding, and the slurry of concrete is not high, it is caused by the change of cement or admixture. In guarantee under the condition of concrete slump, properly reduce the dosage of admixture, to ensure the state of concrete meet the construction requirements, if reduce the dosage of admixture, slump is lower, or there is bleeding phenomenon at the same time, it is the adaptability of admixture and cement is bad, need admixture manufacturer adjusting additive formulation, adding admixtures plastic components. Sand ratio is too low or coarse aggregate gradation can cause segregation, excluding the two reasons after concrete or segregation, cohesion sex is admixture is bad, admixture manufacturers add thickener, improve admixture adhesiveness ${ }^{[6]}$.

\section{Application of water reducing agent}

In the water reducing agent used, it can be used as early strength agent, can accelerate the early strength of concrete, improve the construction schedule, but the application of early strength agent will also bring some impact on construction, such as the ultimate strength of concrete and the decline in the late strength, concrete workability change, etc. Although there is a common type in early strength agent, water reducing agent also can improve the workability of concrete, but the cost is too high, and the early strength agent was found to be of poor quality or use at the time, not easy to cause steel corrosion, impact the quality of engineering. The effective water reducing agent can replace the early strength agent after the matching test, which will not affect the engineering quality and construction cost. In the application of water reducing agent, the performance of concrete will be improved regardless of the climate conditions, including the homogeneity of concrete, the ease of the density and the fluidity, etc.; When the water reducing agent is used, the water cement ratio decreases, the cement dosage is reduced, the concrete production cost is reduced, especially in the preparation of high strength concrete, the water reducing agent is indispensable. In the actual production of the concrete to strictly control the moisture content of sand in the process, the moisture content will lead to concrete water volatile, sand moisture content is too small and increase the adsorption of water reducing agent ${ }^{[7]}$. The water content of sand should be controlled between $4 \%$ and $6 \%$, and the water reducing agent should be avoided directly with the dry sand, and the mixing time should be controlled properly. The mixture of different water reducers should be treated with caution, and the compatibility of cement and admixtures can be verified when necessary.

\section{When the water reducing agent is used, the following questions should be paid attention to}

6.1 ensures that the cement is used to each other. This is the basis of the use of water reducers and must be taken seriously with the adaptability of cement. If the two do not adapt, the effect of reducing water will not reach not only, but also will cause the engineering quality to decrease, the construction cost increases the question.

6.2 accurate choice of water reducing agent. In order to make 
the water reducer function fully, we should choose the water reducer correctly in combination with the actual conditions. Different water reducing agents can not be used in combination to prevent adverse application of concrete quality.

6.3 notice the quality of the water reducer. The quality of water reducing agent has a direct effect on the quality of concrete. As a result of the choice of water reducer, some of the water-reducing agents with poor quality should be prevented to be used in construction ${ }^{[8]}$.

Control of the amount of water agent. Dosage of water reducing agent has a direct impact on the quality of concrete, too little or too much water reducing agent dosage on cannot reach jianshuiji maximum effect, serious can lead to engineering accident, so when used to strictly control the dosage of water reducing agent.

\section{Development trend of water reducing agent}

The research of high performance water reducing agent has become an important branch of concrete material science, and promoted the development of concrete material from low technology to high technology. Water reducing agent industry is developing at a high speed, and many products have entered the Chinese market. In contrast, domestic own technology products is extremely backward, the research of polycarboxylate superplasticizer is still in the stage of laboratory synthesis is simple, there is no mature products in the domestic construction technology based on (there is a considerable gap from industrial production). We should face up to the gap, find out the insufficiency, and enlarge the study of the theory and applied technology. From the report of domestic academic research, domestic experts and scholars on polycarboxylate superplasticizer has been paid enough attention, with the study of chemical synthesis and characterization of polymer reducing agent and its relationship between the chemical structure and properties of the deepening of polycarboxylate superplasticizer will further towards high performance, multi-functional, green, international standard the direction of development, countries all over the world are devoted to the study of polycarboxylate superplasticizer, it will be twenty-first Century superplasticizer research and development trend ${ }^{[9]}$.

\section{Conclusion}

At present, the water reducing agent at home and abroad are widely applied, as admixture of concrete is a kind of important, when use, if the improper control of dosage, water reducing effect will not be able to play out. So, engineering, the variety and quality of water reducing agent to reasonable choice, strictly determine best dosage of water reducing agent, using the correct adding method, ensure that the performance of water reducing agent is the best play, ensure the realization of engineering quality ${ }^{[10]}$.

\section{References}

[1] Wang Min, Li Yue. Research progress of concrete water reducing agent [J]. Building Materials world, 2007, 28 (5): 14-17.

[2] Zhang Xiuzhi, Yang Yongqing, Pei, Meishan. Application and development of superplasticizer [J]. Journal of University of Jinan (NATURAL SCIENCE EDITION), 2004, 18 (2): 139-144.

[3] Zhang Lixin, Bing, Liu Juanyu. Application of $[\mathrm{J}]$. water reducing agent in concrete in Jiangxi building materials, 1998 (JX): 15-18.

[4] Liu Congyan. Study on the application of water reducing agent in commercial concrete [D]. Nanchang University, 2014.

[5] Feng Shiming. The future development trend of high efficiency concrete water reducing agent [J]. Tianjin building materials, 2005 (3): 7-9.

[6] Wang Ling, Tian Pei, Bai Jie, et al. Present situation and future of concrete water reducing agent $[\mathrm{J}]$. China, concrete and cement products, 2008 (5): 1-7.

[7] Wang Guojian, Wei Jingliang. Study on the mechanism of concrete water reducing agent and 
its role of [J]. in Building Materials 2004, 7 (2): 188-193.

[8] Li Weiliang. Performance and application of superplasticizer [J]. communications world, 2011 (6):
109-110.

[9] Chi Yongqing, Liu Huiqing. Research and application progress of concrete superplasticizer [J]. Shanxi chemical engineering, 2003,
23 (4): 36-38.

[10] Zhang Lu. High-range history, current situation and trend of development of agent [J]. industrial construction, 1990 (4): 3-6. 